\title{
Treatment of Stage IV Colon Cancer in the United States: A Patterns-of-Care Analysis
}

Xiang Gao, MD, MPH${ }^{1}$; Amanda R. Kahl, MPH²; Paolo Goffredo, MDㅜ; Albert Y. Lin, MD, MPH³,4 Praveen Vikas, MD; Imran Hassan, $\mathrm{MD}^{1}$; and Mary E. Charlton, $\mathrm{PhD}^{2}$

\begin{abstract}
Background: National guidelines recommend chemotherapy as the mainstay of treatment for stage IV colon cancer, with primary tumor resection (PTR) reserved for patients with symptomatic primary or curable disease. The aims of this study were to characterize the treatment modalities received by patients with stage IV colon cancer and to determine the patient-, tumor-, and hospital-level factors associated with those treatments. Methods: Patients diagnosed with stage IV colon cancer in 2014 were extracted from the SEER Patterns of Care initiative. Treatments were categorized into chemotherapy only, PTR only, PTR + chemotherapy, and none/unknown. Results: The total weighted number of cases was 3,$336 ; 17 \%$ of patients received PTR only, $23 \%$ received chemotherapy only, $41 \%$ received PTR + chemotherapy, and $17 \%$ received no treatment. In multivariable analyses, compared with chemotherapy only, PTR + chemotherapy was associated with being married (odds ratio [OR], 1.9), having bowel obstruction (OR, 2.55), and having perforation (OR, 2.29), whereas older age (OR, 5.95), Medicaid coverage (OR, 2.46), higher $T$ stage $(O R, 3.51)$, and higher $N$ stage $(O R, 6.77)$ were associated with PTR only. Patients who received no treatment did not have more comorbidities or more severe disease burden but were more likely to be older (OR, 3.91) and non-Hispanic African American (OR, 2.92; all $P<.05)$. Treatment at smaller, nonacademic hospitals was associated with PTR ( \pm chemotherapy). Conclusions: PTR was included in the treatment regimen for most patients with stage IV colon cancer and was associated with smaller, nonacademic hospitals. Efforts to improve guideline implementation may be beneficial in these hospitals and also in non-Hispanic African American and older populations.
\end{abstract}

J Natl Compr Canc Netw 2020;18(6):689-699 doi: $10.6004 /$ jnccn. 2020.7533

\footnotetext{
${ }^{1}$ Department of Surgery, Carver College of Medicine, and ${ }^{2}$ Department of Epidemiology, College of Public Health, University of lowa, lowa City, lowa; ${ }^{3}$ Division of Oncology, Department of Medicine, VA Palo Alto Health Care System, Palo Alto, California; ${ }^{4}$ Department of Medicine, Stanford University, Stanford, California; and ${ }^{5}$ Department of Internal Medicine, Carver College of Medicine, University of lowa, lowa City, lowa.
}

\section{Background}

De novo stage IV colon cancer accounts for approximately $22 \%$ of new cases of colon cancer and has an overall 5-year survival of approximately $14 \% .{ }^{1}$ The development of novel targeted agents and their use in combination with chemotherapy over the past 2 decades have correlated with decreases in the frequency of primary tumor resection (PTR). ${ }^{2,3}$ Targeted therapies that include anti-vascular endothelial growth factor (antiVEGF) antibody and anti-epidermal growth factor receptor (anti-EGFR) antibody combined with cytotoxic chemotherapies provide disease control of the primary site and limit complications from the unresected primary site. In fact, median overall survival of patients with unresectable stage IV colorectal cancer (CRC) has improved to 2 to 3 years compared with approximately 1 year during the fluoropyrimidine monotherapy era. ${ }^{4}$ Current NCCN Clinical Practice Guidelines in Oncology (NCCN Guidelines) for Colon Cancer recommend systemic therapy without PTR for unresectable stage IV colon cancer in the absence of bowel obstruction, perforation, substantial bleeding, or tumor-related symptoms. ${ }^{5}$

In 2015, the NCI SEER Program conducted its first Patterns of Care (POC) study in patients with stage IV colon cancer diagnosed in 2014. In addition to the traditional demographic and tumor characteristics collected by SEER, the SEER POC study collected additional variables in a sample of patients from various SEER registries. For stage IV colon cancer, these variables included the presence of bowel perforation or obstruction, specific systemic chemotherapy and targeted therapy agents, molecular pathology testing (KRAS, BRAF, and microsatellite instability [MSI]), comorbidities, and hospital characteristics. Given the complex combination of treatments available to patients with metastatic colon cancer, the objective of this study was to use data from the SEER POC study to examine the patient, tumor, and hospital factors associated with each of the following treatment categories: (1) PTR only, (2) systemic chemotherapy only ( \pm targeted agents), (3) PTR + chemotherapy, 
or (4) no treatment. In addition, we aimed to describe survival by treatment group.

\section{Methods}

\section{Study Population}

The following SEER registries participated in the stage IV colon cancer study: Connecticut, New Jersey, Iowa, Detroit, Kentucky, Louisiana, Atlanta, California, Hawaii, New Mexico, Seattle, and Utah. There were 3,690 cases of stage IV colon cancer diagnosed in 2014 from these registries that were eligible for the POC study. Eligible cases included patients aged $\geq 20$ years whose first and only cancer was a histologically confirmed diagnosis of stage IV colon cancer (based on the 7th edition of the AJCC Cancer Staging Manual) in 2014. Eligible primary site topography codes included C18.0 and C18.2-C18.9; cases of lymphoma of colon (histology codes 9590-9989) or cases that were diagnosed at autopsy or on a death certificate only were excluded. Cases were sampled by patient sex and race/ethnicity from each registry approximately proportionate to registry size. The sampling plan was specified by NCI in which non-Hispanic African Americans, Hispanics, Asians/Pacific Islanders, and Native Alaskans/American Indians were oversampled to provide more stable estimates. Across all participating registries, the POC study ultimately sampled $39 \%$ of eligible cases $(\mathrm{n}=1,445)$.

In this study, we furthermore excluded patients who did not have a confirmed histology of neoplasm, carcinoma, adenocarcinoma, or signet ring cell carcinoma per WHO classification (ICD-O-3 diagnosis codes 8000, 8010, 8140, 8210-8211, 8255, 8261-8263, 8480-8481, and 8490). ${ }^{6}$ A flowchart of patient selection is depicted in Figure 1.

\section{Study Variables}

The POC dataset contained patient variables that included age at diagnosis, sex, race/ethnicity, marital status, health insurance, and Charlson-Deyo comorbidity score. Tumor characteristics included histology, categorized as adenocarcinoma versus other (neoplasm, carcinoma, mucinous, signet ring cell); sidedness classified as right (C18.0, C18.2, C18.3, C18.4), left (C18.5, C18.6, C18.7), or colon not otherwise specified (C18.8, C18.9); tumor grade; tumor stage; MSI status; and KRAS and $B R A F$ mutation status. Information about perforation was abstracted from operative reports, pathology reports, and clinical records, whereas information about bowel obstruction was abstracted from operative or pathology reports only. Hospital bed size and presence of a residency training program were collected for the facility that provided the most definitive therapy. Treatment information was abstracted from patient medical records

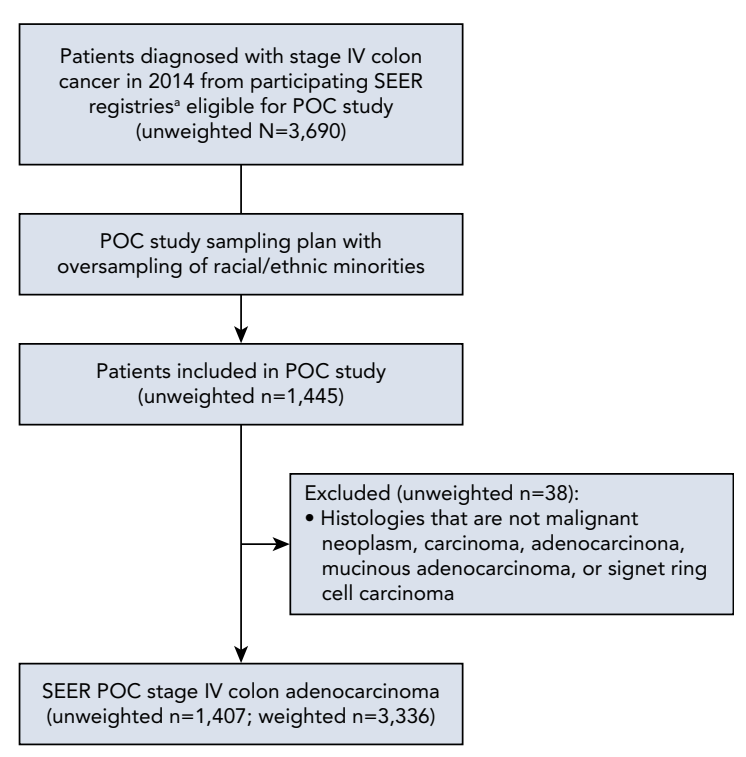

Figure 1. Case selection flow diagram. Abbreviation: POC, patterns of care.

aConnecticut, New Jersey, lowa, Detroit, Kentucky, Louisiana, Atlanta, California, Hawaii, New Mexico, Seattle, and Utah.

and included PTR (yes/no), radiation (yes/no), systemic chemotherapeutic agents, and targeted biologic agents.

For this study, CHAMPUS and Veterans Affairs coverage were categorized as private health insurance. For treatment regimens, "first-line" agents were considered as those given within 7 weeks of diagnosis. Targeted biologic agents were categorized into antiEGFR (cetuximab, panitumumab) and anti-VEGF (bevacizumab, ramucirumab, ziv-aflibercept) antibodies. Treatment groups were defined by whether patients had PTR only, chemotherapy only, both PTR and chemotherapy, or no treatment (which also included patients with unknown treatment, who made up $1.8 \%$ of the overall population). SEER registries were grouped into the following regional categories: (1) Northeast: Connecticut and New Jersey; (2) North Central: Iowa and Detroit; (3) South: Kentucky, Louisiana, and Atlanta; and (4) West: California, Hawaii, New Mexico, Seattle, and Utah.

\section{Statistical Analysis}

Sampling weights were applied to account for the sampling procedures and oversampling of nonwhite patients. Chi-square tests were used to compare patient, tumor, and facility characteristics among the 4 treatment groups. Multinomial logistic regression, which allows simultaneous comparison of multiple categories against a reference category, was used to analyze each treatment group compared with the chemotherapy-only group as the reference. Kaplan-Meier curves (unweighted) and 


\section{Table 1. Patient, Tumor, and Hospital Characteristics by Treatment Type}

\begin{tabular}{|c|c|c|c|c|c|c|c|}
\hline \multirow[b]{2}{*}{ Characteristic } & \multicolumn{2}{|c|}{ Total $^{a}$} & \multicolumn{4}{|c|}{ Weighted } & \multirow[b]{2}{*}{$P$ Value } \\
\hline & $\underset{\mathbf{n}}{\text { Unweighted }}$ & $\begin{array}{l}\text { Weighted } \\
\text { n (\%) }\end{array}$ & $\begin{array}{c}\text { Chemotherapy } \\
\text { Only }\end{array}$ & $\begin{array}{c}\text { PTR + } \\
\text { Chemotherapy }\end{array}$ & $\begin{array}{l}\text { PTR } \\
\text { Only }\end{array}$ & $\begin{array}{c}\text { None/ } \\
\text { Unknown }\end{array}$ & \\
\hline Total, $n$ & 1,407 & $3,336(100)$ & 755 & 1,367 & 537 & 564 & \\
\hline Age at diagnosis, y & & & & & & & $<.0001$ \\
\hline$<55$ & 368 & $766(23)$ & $22 \%$ & $34 \%$ & $9 \%$ & $9 \%$ & \\
\hline $55-64$ & 399 & $903(27)$ & $35 \%$ & $28 \%$ & $19 \%$ & $21 \%$ & \\
\hline$\geq 75$ & 306 & $825(25)$ & $19 \%$ & $13 \%$ & $44 \%$ & $43 \%$ & \\
\hline Sex & & & & & & & .008 \\
\hline Male & 715 & $1,705(51)$ & $50 \%$ & $57 \%$ & $41 \%$ & $47 \%$ & \\
\hline Female & 692 & $1,631(49)$ & $50 \%$ & $43 \%$ & $59 \%$ & $53 \%$ & \\
\hline Race/Ethnicity ${ }^{c}$ & & & & & & & .008 \\
\hline Asian/Pacific Islander & 263 & $315(9)$ & $9 \%$ & $8 \%$ & $11 \%$ & $11 \%$ & \\
\hline Insurance & & & & & & & $<.0001$ \\
\hline Private & 775 & $2,014(60)$ & $64 \%$ & $66 \%$ & $48 \%$ & $51 \%$ & \\
\hline Any Medicaid & 362 & $711(21)$ & $18 \%$ & $20 \%$ & $28 \%$ & $25 \%$ & \\
\hline Medicare only & 204 & $481(14)$ & $13 \%$ & $10 \%$ & $22 \%$ & $20 \%$ & \\
\hline None/Unknown & 66 & $130(4)$ & $5 \%$ & $4 \%$ & $2 \%$ & $4 \%$ & \\
\hline Marital Status & & & & & & & .0001 \\
\hline Married & 686 & $1,725(52)$ & $48 \%$ & $61 \%$ & $40 \%$ & $46 \%$ & \\
\hline Unmarried/Unknown & 721 & $1,611(48)$ & $52 \%$ & $39 \%$ & $60 \%$ & $54 \%$ & \\
\hline Charlson-Deyo comorbidity score & & & & & & & .001 \\
\hline West & 723 & $1,731(52)$ & $48 \%$ & $52 \%$ & $62 \%$ & $50 \%$ & \\
\hline Hospital bed size ${ }^{d}$ & & & & & & & $<.0001$ \\
\hline$<200$ & 321 & $832(25)$ & $16 \%$ & $31 \%$ & $27 \%$ & $23 \%$ & \\
\hline $200-399$ & 479 & $1,133(35)$ & $28 \%$ & $32 \%$ & $47 \%$ & $37 \%$ & \\
\hline$\geq 400$ & 583 & $1,319(40)$ & $57 \%$ & $37 \%$ & $26 \%$ & $40 \%$ & \\
\hline Residency program & & & & & & & $<.0001$ \\
\hline Yes & 848 & $1,886(57)$ & $73 \%$ & $53 \%$ & $43 \%$ & $56 \%$ & \\
\hline No/Unknown & 559 & $1,451(43)$ & $27 \%$ & $47 \%$ & $57 \%$ & $44 \%$ & \\
\hline Sidedness & & & & & & & $<.0001$ \\
\hline Right & 671 & $1,547(46)$ & $44 \%$ & $45 \%$ & $60 \%$ & $44 \%$ & \\
\hline Left & 592 & $1,432(43)$ & $43 \%$ & $52 \%$ & $32 \%$ & $30 \%$ & \\
\hline Colon, NOS & 144 & $358(11)$ & $13 \%$ & $3 \%$ & $8 \%$ & $27 \%$ & \\
\hline Histology & & & & & & & .22 \\
\hline Adenocarcinoma & 1,255 & $2,992(90)$ & $88 \%$ & $91 \%$ & $91 \%$ & $85 \%$ & \\
\hline Othere & 152 & $345(10)$ & $12 \%$ & $9 \%$ & $9 \%$ & $15 \%$ & \\
\hline
\end{tabular}


Table 1. Patient, Tumor, and Hospital Characteristics by Treatment Type (cont.)

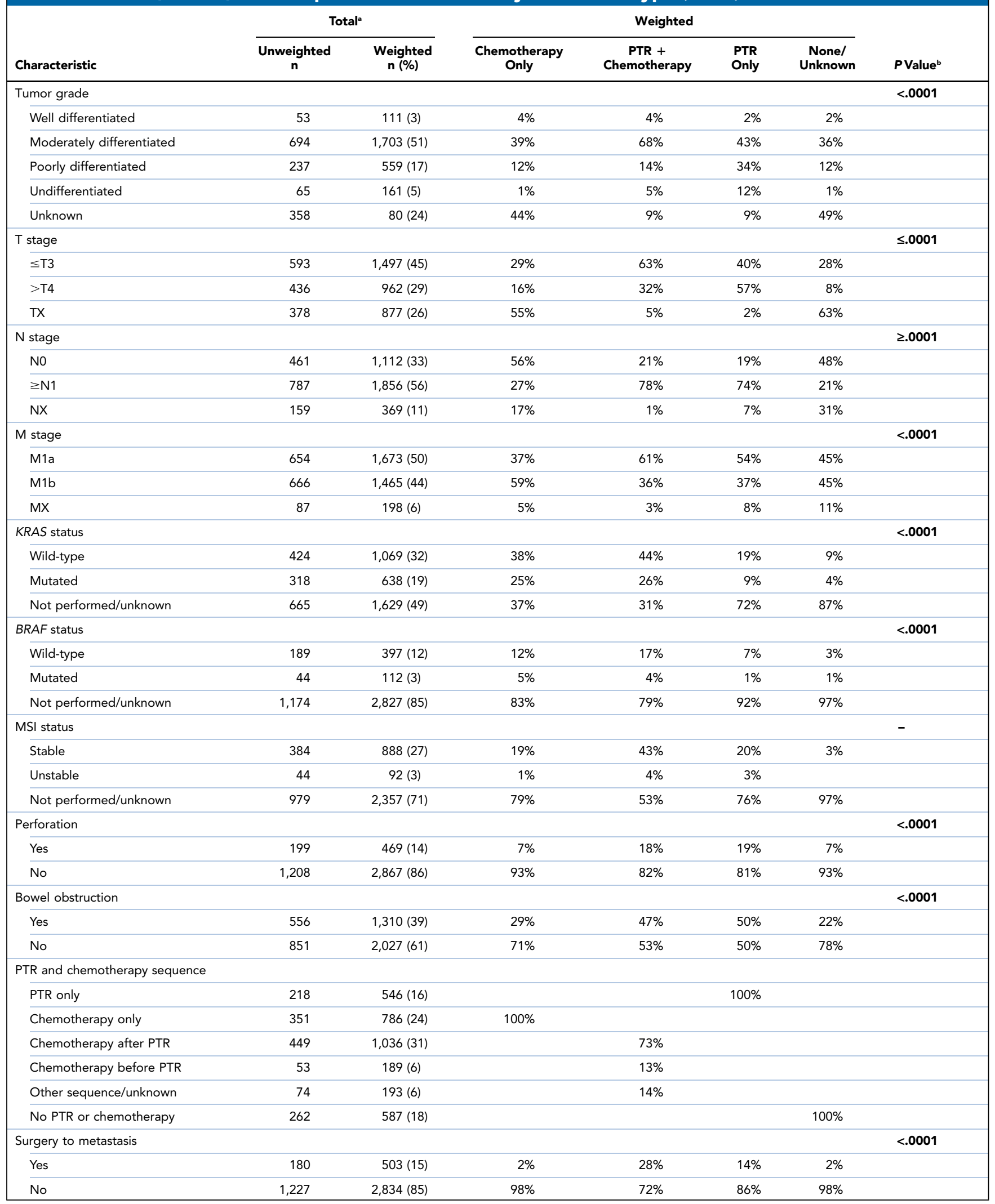




\begin{tabular}{|c|c|c|c|c|c|c|c|}
\hline Characteristic & $\begin{array}{c}\text { Unweighted } \\
n\end{array}$ & $\begin{array}{c}\text { Weighted } \\
\text { n (\%) }\end{array}$ & $\begin{array}{c}\text { Chemotherapy } \\
\text { Only }\end{array}$ & $\begin{array}{c}\text { PTR + } \\
\text { Chemotherapy }\end{array}$ & $\begin{array}{l}\text { PTR } \\
\text { Only }\end{array}$ & $\begin{array}{c}\text { None/ } \\
\text { Unknown }\end{array}$ & PValue ${ }^{b}$ \\
\hline \multicolumn{8}{|l|}{ Radiation } \\
\hline Yes & 60 & $113(3)$ & & & & & \\
\hline None & 480 & $1,132(34)$ & & & $100 \%$ & $100 \%$ & \\
\hline Systemic only & 263 & $717(21)$ & $31 \%$ & $33 \%$ & & & \\
\hline Systemic and targeted therapy & 664 & $1,488(45)$ & $69 \%$ & $67 \%$ & & & \\
\hline \multicolumn{8}{|l|}{ VEGF inhibitor } \\
\hline Yes & 603 & $1,335(40)$ & $64 \%$ & $59 \%$ & & & \\
\hline No & 1,244 & $2,935(88)$ & $83 \%$ & $82 \%$ & $100 \%$ & $100 \%$ & \\
\hline
\end{tabular}

Abbreviations: EGFR, epidermal growth factor receptor; MSI, microsatellite instability; NOS, not otherwise specified; PTR, primary tumor resection; VEGF, vascular endothelial growth factor.

alncludes 113 patients who received radiation who are excluded from treatment groups.

bBold indicates statistically significant $P$ values.

c17 unweighted cases had race of other/unknown.

d24 cases had missing hospital bed size.

eNeoplasm, carcinoma, mucinous, and signet ring cell.

Cox proportional hazards (weighted) were used to analyze overall survival between treatment groups. All variables listed earlier were considered for inclusion in multinomial and Cox models using stepwise selection. A $P$ value $<.05$ was considered statistically significant. Patients who received radiation (weighted $\mathrm{n}=113$ ) were included in univariable analyses but excluded from multivariable and survival analyses. Patients with missing variables were not included in multivariable models. Analyses were conducted using SAS 9.4 (SAS Institute Inc.).

\section{Results}

\section{Overall Population Characteristics}

Of 1,445 (unweighted) patients diagnosed with stage IV colon cancer in the SEER POC dataset, 38 were excluded who did not meet histologic criteria. The final cohort included a total weighted sample of 3,336 patients. Mean cohort age was 63 years; $51 \%$ were men and $63 \%$ were non-Hispanic white (Table 1). Of the weighted sample, $17 \%$ of patients received PTR only, 23\% chemotherapy only, $41 \%$ PTR + chemotherapy, and $17 \%$ no treatment. Among patients who received PTR + chemotherapy, $73 \%$ had PTR first, $13 \%$ had chemotherapy first, and the sequence was unknown in 14\%; most of these patients (72\%) did not have a metastasectomy. Across all patients, approximately one-half received a biologic agent as a part of their treatment (40\% anti-VEGF; $12 \%$ antiEGFR). Geographically, PTR + chemotherapy was the most frequent treatment in all regions $(42 \%-46 \%)$, except in the North Central region, where chemotherapy only was used most frequently (33\%) (Figure 2).

Of the entire weighted cohort, 437 patients (13\%) died within 30 days of diagnosis. These patients were older; had higher Charlson-Deyo comorbidity index scores; more often had right-sided primaries, poorly differentiated or unknown tumor grade, unknown T stage, unknown or N0 stage, and unknown KRAS, BRAF, or MSI status; and less often had bowel obstruction or surgery to metastasis (all $P \leq .04$ ). Exclusion of these patients from multivariable analyses did not change the direction of the measures of association, and they were therefore included in the final analyses.

\section{Factors Associated With Specific Treatments}

In multivariable analysis, compared with patients who received chemotherapy only, those who received PTR + chemotherapy were more likely to be married, have node-positive disease, have bowel perforation and/or obstruction, and be treated in smaller, nonacademic hospitals. They were less likely to present with Mlb disease (Table 2).

Patients who underwent PTR only were more likely to be older, have Medicaid insurance coverage, and present with undifferentiated tumor grade, more advanced $\mathrm{T}$ and $\mathrm{N}$ stages, and unknown KRAS status. They were also more likely to have bowel obstruction and 


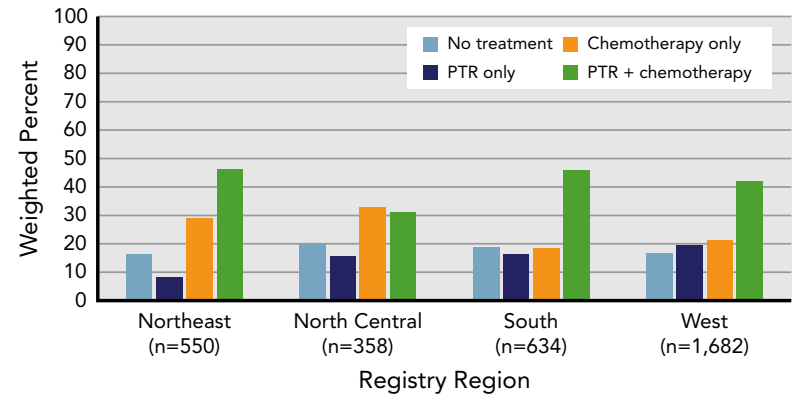

Figure 2. Weighted percentage of treatment type in stage IV colon cancer, by SEER Registry region. Northeast: Connecticut and New Jersey; North Central: lowa and Detroit; South: Kentucky, Louisiana, and Atlanta; West: California, Hawaii, New Mexico, Seattle, and Utah. Abbreviation: PTR, primary tumor resection.

receive care from smaller hospitals. These patients were less likely to have Mlb disease. Patients who underwent no treatment were more likely to be older, be non-Hispanic African American, and have unknown KRAS and/or MSI status (Table 2).

\section{Survival Analyses}

Overall median follow-up of the entire cohort was 11.5 months. In unadjusted Kaplan-Meier analyses, median survival between treatment groups varied significantly: chemotherapy only, 14 months; PTR only, 5 months; no treatment, 2 months; and PTR + chemotherapy, $>24$ months (median follow-up, 15 months [Figure 3]; number at risk not shown because of small numbers). After controlling for covariables, those receiving PTR + chemotherapy had half the risk of death (hazard ratio, 0.40; 95\% CI, 0.29-0.56) compared with those who received chemotherapy only. Conversely, those who received PTR only or no treatment had 2 to 3 times the risk of death of patients who had chemotherapy only (Table 3).

\section{Discussion}

In this study of POC in stage IV colon cancer, more than half of patients (57\%) received PTR as a part of their treatment, with PTR + chemotherapy being the most common treatment modality. In adjusted analyses, treatment patterns varied by disease factors but also by patient race, insurance status, and hospital type. Patients who received PTR + chemotherapy (vs chemotherapy alone) were more likely to be married, have nodepositive disease, have lower metastatic burden, and present with bowel perforation and/or obstruction. Patients who received PTR only were older, covered by Medicaid, and more likely to have bowel obstruction and advanced disease but lower metastatic burden. Patients who received no treatment were older, were non-Hispanic African American, and had unknown genetic markers. Overall, patients receiving nonchemotherapy-only treatment were more likely to be treated at smaller hospitals and hospitals without a residency program.

Previous studies of stage IV CRC in SEER have also found patient and tumor characteristics to be independently associated with PTR. These studies, which included patients with rectal cancer and did not adjust for POC variables such as hospital size and type, molecular pathology biomarkers, and presence of bowel perforation and obstruction, found that younger, female, and married patients with higher tumor grade were more likely to receive PTR \pm chemotherapy. ${ }^{2,7}$ In our study, factors independently associated with PTR + chemotherapy differed from those associated with PTR only, suggesting that these are two distinct patient populations, the latter of which are older, enrolled in Medicaid, and had more advanced disease than patients who received chemotherapy only.

The frequency of PTR in our study is consistent with other studies using national data that showed that although PTR frequency has been decreasing over the past several decades, it is still used in more than half of patients with unresectable stage IV metastatic colon cancer. ${ }^{2,3,8}$ Examination of PTR rates in patients with stage IV CRC in the SEER population reported a decline of PTR use from $74.5 \%$ in 1988 to $57.4 \%$ in 2010 , with a reduction rate of $2.4 \%$ per year between 2001 and $2010 .^{2}$ Our study showed that $51 \%$ of patients underwent PTR in 2015, suggesting further, albeit slow, decline of PTR rates between 2010 and 2015.

Within the past decade, multiple retrospective studies have found survival benefit in patients with stage IV colon cancer who underwent tumor resection versus those who did not. However, each of these studies has been limited by selection bias because patient and/or disease factors, such as subsequent systemic treatment, tumor genetics, and metastatic burden, were not available. ${ }^{9-13}$ As a result, current NCCN Guidelines for Colon Cancer recommend PTR only for symptomatic disease or for patients with both resectable primary tumors and metastases. ${ }^{5}$ In our study, we found that patients who underwent PTR more frequently presented with symptoms and had lower metastatic burden (Mla vs Mlb), and we also found that patients who received PTR + chemotherapy were more often $K R A S$ or $B R A F$ wild-type. This latter finding lends credence to the observation that selection bias may contribute to the improved survival of patients who underwent resection.

Previous studies have found that most (77\%-90\%) patients with stage IV colon cancer present with unresectable disease. ${ }^{14,15}$ In this context, PTR may be 


\section{Table 2. Multinomial Analysis of Association Between Patient, Tumor, and Hospital Characteristics and} Treatment

\begin{tabular}{|c|c|c|c|c|c|c|}
\hline \multirow[b]{2}{*}{ Characteristic } & \multicolumn{2}{|c|}{$\begin{array}{l}\text { PTR + Chemotherapy vs } \\
\text { Chemotherapy Only } \\
(n=1,347)\end{array}$} & \multicolumn{2}{|c|}{$\begin{array}{c}\text { PTR Only vs } \\
\text { Chemotherapy Onlya } \\
(n=533)\end{array}$} & \multicolumn{2}{|c|}{$\begin{array}{c}\text { None vs Chemotherapy Only } \\
(n=555)\end{array}$} \\
\hline & OR & $95 \% \mathrm{Cl}$ & OR & $95 \% \mathrm{Cl}$ & OR & $95 \% \mathrm{Cl}$ \\
\hline$<55$ & & Ref & & Ref & & Ref \\
\hline $55-64$ & 0.76 & $(0.38-1.50)$ & 1.00 & $(0.43-2.33)$ & 1.22 & $(0.56-2.65)$ \\
\hline \multicolumn{7}{|l|}{ Sex } \\
\hline Male & & Ref & & Ref & & Ref \\
\hline Female & 0.95 & $(0.59-1.52)$ & 1.58 & $(0.88-2.85)$ & 1.18 & $(0.69-2.03)$ \\
\hline \multicolumn{7}{|l|}{ Race/Ethnicity ${ }^{b}$} \\
\hline Non-Hispanic white & & Ref & & Ref & & Ref \\
\hline \multicolumn{7}{|l|}{ Insurance } \\
\hline Private & & Ref & & Ref & & Ref \\
\hline Any Medicaid & 1.66 & $(0.90-3.09)$ & 2.46 & $(1.20-5.04)$ & 1.39 & $(0.73-2.66)$ \\
\hline Medicare & 1.05 & $(0.48-2.31)$ & 1.78 & $(0.76-4.15)$ & 0.79 & $(0.36-1.72)$ \\
\hline None/Unknown & 0.49 & $(0.20-1.16)$ & 1.01 & $(0.22-4.54)$ & 1.20 & $(0.37-3.90)$ \\
\hline \multicolumn{7}{|l|}{ Marital status } \\
\hline Married & & Ref & & Ref & & Ref \\
\hline Unmarried/Unknown & 0.53 & $(0.32-0.88)$ & 1.08 & $(0.60-1.93)$ & 1.03 & $(0.61-1.73)$ \\
\hline \multicolumn{7}{|l|}{ Charlson-Deyo comorbidity score } \\
\hline 0 & & Ref & & Ref & & Ref \\
\hline West & & Ref & & Ref & & Ref \\
\hline \multicolumn{7}{|l|}{ Hospital bed size ${ }^{c}$} \\
\hline$<200$ & 2.51 & (1.33-4.73) & 2.13 & $(0.90-5.01)$ & 1.56 & $(0.73-3.33)$ \\
\hline $200-399$ & 1.73 & $(0.94-3.16)$ & 2.61 & $(1.34-5.08)$ & 1.36 & $(0.74-2.50)$ \\
\hline$\geq 400$ & & Ref & & Ref & & Ref \\
\hline \multicolumn{7}{|l|}{ Hospital residency } \\
\hline Yes & & Ref & & Ref & & Ref \\
\hline No/Unknown & 1.78 & $(1.04-3.04)$ & 1.75 & $(0.91-3.40)$ & 1.60 & $(0.79-3.22)$ \\
\hline \multicolumn{7}{|l|}{ Sidedness } \\
\hline Right & 0.75 & $(0.45-1.25)$ & 0.89 & $(0.49-1.62)$ & 0.87 & $(0.45-1.68)$ \\
\hline Left & & Ref & & Ref & & Ref \\
\hline Colon, NOS & 0.93 & $(0.22-3.90)$ & 2.02 & $(0.50-8.23)$ & 1.58 & $(0.72-3.45)$ \\
\hline \multicolumn{7}{|l|}{ Histology } \\
\hline Adenocarcinoma & & Ref & & Ref & & Ref \\
\hline Other ${ }^{d}$ & 1.27 & $(0.57-2.81)$ & 1.51 & $(0.60-3.81)$ & 1.17 & $(0.54-2.55)$ \\
\hline
\end{tabular}


Table 2. Multinomial Analysis of Association Between Patient, Tumor, and Hospital Characteristics and Treatment (cont.)

\begin{tabular}{|c|c|c|c|c|c|c|}
\hline \multirow[b]{2}{*}{ Characteristic } & \multicolumn{2}{|c|}{$\begin{array}{c}\text { PTR + Chemotherapy vs } \\
\text { Chemotherapy Onlya } \\
(n=1,347)\end{array}$} & \multicolumn{2}{|c|}{$\begin{array}{l}\text { PTR Only vs } \\
\text { Chemotherapy Only } \\
(n=533)\end{array}$} & \multicolumn{2}{|c|}{$\begin{array}{l}\text { None vs Chemotherapy Onlya } \\
(n=555)\end{array}$} \\
\hline & OR & $95 \% \mathrm{Cl}$ & OR & $95 \% \mathrm{Cl}$ & OR & $95 \% \mathrm{Cl}$ \\
\hline Well-differentiated & & Ref & & Ref & & Ref \\
\hline Moderately differentiated & 1.14 & $(0.44-2.95)$ & 2.25 & $(0.51-10.02)$ & 0.79 & $(0.16-3.90)$ \\
\hline Unknown & 0.20 & $(0.07-0.61)$ & 0.33 & $(0.06-1.74)$ & 0.86 & $(0.17-4.39)$ \\
\hline \multicolumn{7}{|l|}{ T stage } \\
\hline$\leq \mathrm{T} 3$ & & Ref & & Ref & & Ref \\
\hline$>\mathrm{T} 4$ & 1.24 & $(0.67-2.32)$ & 3.51 & (1.72-7.18) & 0.54 & $(0.23-1.26)$ \\
\hline $\mathrm{NX}$ & 0.73 & $(0.21-2.48)$ & 3.31 & $(1.06-10.28)$ & 1.81 & $(0.90-3.62)$ \\
\hline \multicolumn{7}{|l|}{ M stage } \\
\hline M1a & & Ref & & Ref & & Ref \\
\hline M1b & 0.32 & $(0.19-0.53)$ & 0.22 & $(0.12-0.39)$ & 0.63 & $(0.37-1.08)$ \\
\hline$M X$ & 0.62 & $(0.22-1.74)$ & 1.31 & $(0.42-4.08)$ & 2.27 & $(0.90-5.70)$ \\
\hline \multicolumn{7}{|l|}{ KRAS status } \\
\hline Wild-type & & Ref & & Ref & & Ref \\
\hline Mutated & 0.74 & $(0.41-1.33)$ & 0.70 & $(0.30-1.63)$ & 0.73 & $(0.23-2.31)$ \\
\hline Not performed/unknown & 0.94 & $(0.52-1.70)$ & 3.93 & $(1.77-8.70)$ & 10.42 & $(4.87-22.29)$ \\
\hline \multicolumn{7}{|l|}{ BRAF status } \\
\hline Not performed/unknown & 0.38 & $(0.21-0.70)$ & 0.70 & $(0.35-1.41)$ & 8.54 & $(3.18-22.93)$ \\
\hline \multicolumn{7}{|l|}{ Perforation } \\
\hline Yes & 2.29 & $(1.18-4.42)$ & 2.00 & $(0.96-4.15)$ & 0.62 & $(0.23-1.70)$ \\
\hline No & & Ref & & Ref & & Ref \\
\hline \multicolumn{7}{|l|}{ Bowel obstruction } \\
\hline Yes & 2.55 & $(1.54-4.21)$ & 3.13 & $(1.67-5.86)$ & 0.64 & $(0.35-1.16)$ \\
\hline No & & Ref & & Ref & & Ref \\
\hline
\end{tabular}

Values with $P<.05$ are in bold.

Abbreviations: MSI, microsatellite instability; NOS, not otherwise specified; OR, odds ratio; PTR, primary tumor resection.

aChemotherapy only is the reference $(n=722)$.

b17 cases had race of other/unknown.

'24 cases had missing hospital bed size.

dNeoplasm, carcinoma, mucinous, and signet ring cell.

overused, especially when considering that $72 \%$ of patients who underwent PTR + chemotherapy in this study did not undergo a metastasectomy, suggesting that they did not benefit from the curative intent of
PTR and may have been at higher risk of morbidity and mortality. ${ }^{16,17}$ In addition, only $43 \%$ of PTRs in this study were performed in patients without bowel perforation and/or obstruction. 


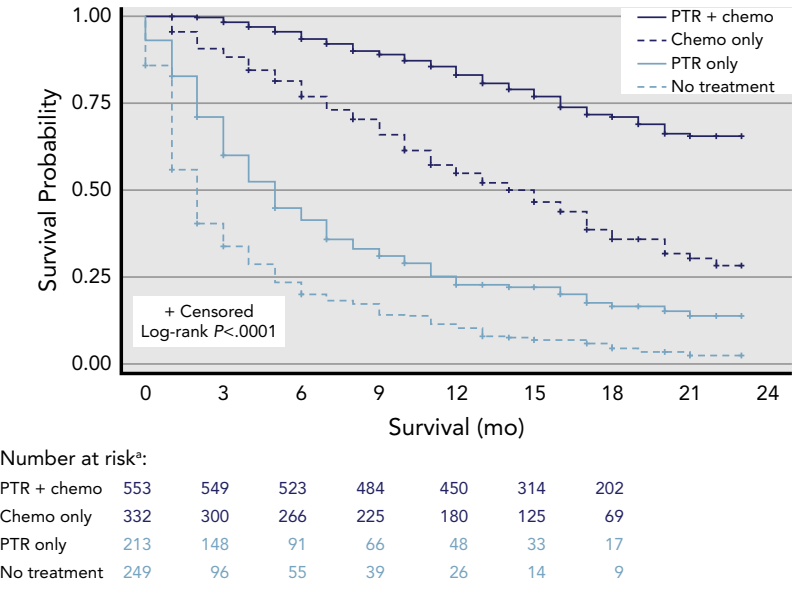

Figure 3. Kaplan-Meier survival plot for patients with stage IV colon cancer, by treatment $(n=1,347)$.

Abbreviations: Chemo, chemotherapy; PTR, primary tumor resection.

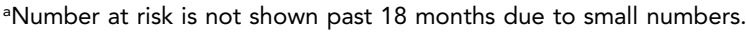

After controlling for patient and tumor factors, we found that treatment at smaller hospitals and those without a residency program were consistent predictors of receiving PTR. Previous studies have shown that hospitals with a low volume of services are less likely to perform metastasectomies, provide palliative care, or use multiagent chemotherapy, and that patients in community programs were more likely to receive PTR. ${ }^{18,19}$ Hospital size and type may be proxies for regional differences related to rurality and provider availability, both of which have been shown to affect cancer outcomes. ${ }^{20-23}$ Future studies should address the extent to which these treatment variations are a result of appropriate differences in patient selection versus knowledge gaps or poor resource allocation.

Approximately $17 \%$ of our study population received no treatment, and these patients were more likely to be older and non-Hispanic African American. Previous results derived from a large population-based database of 37 cancer registries in 2017 showed that African Americans with distant disease in colon cancer had a 5-year net survival of $7.9 \%$ compared with $11.4 \%$ in white individuals. ${ }^{24}$ This higher mortality among white patients may be partially due to the differences in treatment regimens received by non-Hispanic African Americans identified in our study. Although treatment decision is ultimately subject to patient preference, non-Hispanic African Americans who underwent no treatment did not have more comorbidities or more severe disease burden than those who received chemotherapy only, raising the possibility that receiving no treatment may reflect inadequate access to care or poor patient education. A 2005 SEER study showed that African American patients with stage III colon cancer initiated chemotherapy less frequently despite being just as likely

\begin{tabular}{|c|c|c|}
\hline Characteristic & HR & $95 \% \mathrm{Cl}$ \\
\hline \multicolumn{3}{|l|}{ Age at diagnosis, y } \\
\hline$<55$ & & Ref \\
\hline $55-64$ & 1.23 & $(0.96-1.57)$ \\
\hline $65-74$ & 1.29 & $(0.99-1.68)$ \\
\hline$\geq 75$ & 1.78 & $(1.39-2.27)$ \\
\hline \multicolumn{3}{|l|}{ Sex } \\
\hline Male & & Ref \\
\hline Female & 0.89 & $(0.76-1.05)$ \\
\hline \multicolumn{3}{|l|}{ Race/Ethnicity ${ }^{a}$} \\
\hline Non-Hispanic white & & Ref \\
\hline Non-Hispanic African American & 0.99 & $(0.81-1.20)$ \\
\hline Hispanic & 0.71 & $(0.55-0.92)$ \\
\hline Asian/Pacific Islander & 0.81 & $(0.66-1.01)$ \\
\hline \multicolumn{3}{|l|}{ Insurance } \\
\hline Private & & Ref \\
\hline Any Medicaid & 1.19 & $(0.97-1.45)$ \\
\hline Medicare & 0.97 & $(0.75-1.23)$ \\
\hline None/Unknown & 1.64 & $(1.22-2.21)$ \\
\hline \multicolumn{3}{|l|}{ Marital Status } \\
\hline Married & & Ref \\
\hline Unmarried/Unknown & 1.10 & $(0.91-1.32)$ \\
\hline \multicolumn{3}{|l|}{ Charlson-Deyo comorbidity score } \\
\hline 0 & & Ref \\
\hline 1 & 1.36 & $(1.10-1.67)$ \\
\hline$\geq 2$ & 1.22 & $(0.93-1.60)$ \\
\hline \multicolumn{3}{|l|}{ Registry region } \\
\hline North Central & 0.98 & $(0.76-1.28)$ \\
\hline Northeast & 1.09 & $(0.86-1.37)$ \\
\hline South & 1.07 & $(0.86-1.34)$ \\
\hline West & & Ref \\
\hline \multicolumn{3}{|l|}{ Hospital bed size ${ }^{b}$} \\
\hline$<200$ & 1.00 & $(0.78-1.27)$ \\
\hline $200-399$ & 1.21 & $(0.98-1.48)$ \\
\hline$\geq 400$ & & Ref \\
\hline \multicolumn{3}{|l|}{ Residency program } \\
\hline Yes & & Ref \\
\hline No/Unknown & 1.17 & $(0.96-1.42)$ \\
\hline \multicolumn{3}{|l|}{ Sidedness } \\
\hline Right & 1.37 & (1.13-1.65) \\
\hline Left & & Ref \\
\hline Colon, NOS & 1.57 & (1.16-2.12) \\
\hline \multicolumn{3}{|l|}{ Histology } \\
\hline Adenocarcinoma & & Ref \\
\hline Otherc & 1.21 & $(0.96-1.54)$ \\
\hline
\end{tabular}

(continued on next page) 


\begin{tabular}{|c|c|c|}
\hline Characteristic & HR & $95 \% \mathrm{Cl}$ \\
\hline \multicolumn{3}{|l|}{ Tumor grade } \\
\hline Well-differentiated & & Ref \\
\hline Moderately differentiated & 1.06 & $(0.69-1.62)$ \\
\hline Poorly differentiated & 1.25 & $(0.80-1.97)$ \\
\hline Undifferentiated & 1.29 & $(0.77-2.16)$ \\
\hline Unknown & 1.30 & $(0.83-2.04)$ \\
\hline \multicolumn{3}{|l|}{ T stage } \\
\hline$\leq \mathrm{T} 3$ & & Ref \\
\hline$>\mathrm{T} 4$ & 1.22 & $(0.98-1.53)$ \\
\hline TX & 1.20 & $(0.93-1.54)$ \\
\hline \multicolumn{3}{|l|}{$\mathrm{N}$ stage } \\
\hline No & & Ref \\
\hline$\geq \mathrm{N} 1$ & 1.17 & $(0.93-1.47)$ \\
\hline NX & 0.91 & $(0.67-1.23)$ \\
\hline \multicolumn{3}{|l|}{ M stage } \\
\hline M1a & & Ref \\
\hline M1b & 1.08 & $(0.91-1.28)$ \\
\hline $\mathrm{MX}$ & 0.56 & $(0.34-0.94)$ \\
\hline \multicolumn{3}{|l|}{ KRAS status } \\
\hline Wild-type & & Ref \\
\hline Mutated & 1.03 & $(0.81-1.32)$ \\
\hline Not performed/unknown & 1.19 & $(0.94-1.49)$ \\
\hline \multicolumn{3}{|l|}{ BRAF status } \\
\hline Wild-type & & Ref \\
\hline Mutated & 0.78 & $(0.45-1.37)$ \\
\hline Not performed/unknown & 1.16 & $(0.87-1.55)$ \\
\hline \multicolumn{3}{|l|}{ MSI status } \\
\hline Stable & & Ref \\
\hline Unstable & 1.04 & $(0.58-1.86)$ \\
\hline Not performed/unknown & 1.22 & $(0.98-1.51)$ \\
\hline \multicolumn{3}{|l|}{ Perforation } \\
\hline Yes & 1.03 & $(0.81-1.32)$ \\
\hline No & & Ref \\
\hline \multicolumn{3}{|l|}{ Bowel obstruction } \\
\hline Yes & 1.23 & $(1.04-1.44)$ \\
\hline No & & Ref \\
\hline \multicolumn{3}{|l|}{ Surgery to metastasis } \\
\hline Yes & & Ref \\
\hline No & 1.56 & $(1.18-2.08)$ \\
\hline \multicolumn{3}{|l|}{ Treatment group } \\
\hline PTR only & 1.75 & $(1.26-2.43)$ \\
\hline Chemotherapy only & & Ref \\
\hline PTR + chemotherapy & 0.40 & $(0.29-0.56)$ \\
\hline No treatment/unknown & 3.26 & $(2.58-4.11)$ \\
\hline
\end{tabular}

Values with $P<.05$ are in bold.

Abbreviations: HR, hazard ratio; MSI, microsatellite instability; NOS, not otherwise specified; PTR, primary tumor resection.

17 cases had race of other/unknown.

b24 cases had missing hospital bed size.

cNeoplasm, carcinoma, mucinous, and signet ring cell. to see an oncologist as white patients. Although age and lower socioeconomic status in African American patients explained some of the disparity, fatalistic attitudes, stigmas related to cancer, aversions to treatment, and misconceptions about the healthcare system may have driven the remaining disparity. ${ }^{25}$ Efforts are needed to identify barriers to treatment and ensure informed decision-making by African Americans and older populations.

Median survival showed striking distinctions by treatment group, ranging from 2 months to $>24$ months, and in adjusted analysis, patients who underwent PTR + chemotherapy had a much lower risk of death. It is important to note that because of the inability to adjust for variables such as treatment intent, functional status, and patient preference, selection bias is almost certainly a major factor, and results of the survival analyses cannot be interpreted as favoring any treatment. Although PTR is used frequently, it is not associated with greater mortality risk overall when used in conjunction with chemotherapy. Future studies should investigate whether patient subpopulations (eg, symptomatic vs asymptomatic, resectable vs unresectable) are receiving guideline-recommended care.

This study has several limitations. We were not able to control for other factors important in treatment decision-making, which limits the conclusions that can be drawn from our multivariable analyses. Furthermore, the SEER POC initiative does not capture other symptoms, such as persistent bleeding, or the severity of symptoms that may necessitate PTR. Despite these limitations, a major strength of this study is the ability to describe treatment patterns specific to stage IV colon cancer (as opposed to CRC) in a nationally representative sample while correcting for previously unknown information on bowel perforation or obstruction, genetic markers, comorbidities, and hospital characteristics.

\section{Conclusions}

Across the United States, PTR is frequently used in the treatment of stage IV colon cancer despite low proportions of metastasectomies. Treatment patterns also vary by hospital characteristics and patient race/ethnicity and insurance status. Support for guideline implementation may be particularly beneficial in smaller, nonacademic hospitals. Further efforts are also needed to address barriers to care in nonHispanic African Americans and older populations to ensure that these groups receive optimal cancer treatment. 
Author contributions: Study concept and design: Gao, Goffredo, Hassan, Charlton. Data analysis and interpretation: All authors. Manuscript preparation: Gao.

Disclosures: Dr. Lin has disclosed that he is a scientific advisor for Eisai. The remaining authors have disclosed that they have not received any financial consideration from any person or organization to support the preparation, analysis, results, or discussion of this article.
Funding: This work was supported by funding from the NIH (CA148062) and funding to Dr. Charlton from the $\mathrm{NCl}$ (HHSN261201300020I and P30 CA086862).

Correspondence: Mary E. Charlton, PhD, Department of Epidemiology, College of Public Health, University of lowa, 145 North Riverside Drive, Room S453 CPHB, lowa City, IA 52242. Email: mary-charlton@uiowa.edu

\section{References}

1. National Cancer Institute Surveillance, Epidemiology, and End Results Program. Cancer Stat Facts: Colorectal Cancer. Accessed April 30, 2020. Available at: https://seer.cancer.gov/statfacts/html/colorect.html

2. Hu CY, Bailey CE, You YN, et al. Time trend analysis of primary tumor resection for stage IV colorectal cancer: less surgery, improved survival. JAMA Surg 2015;150:245-251.

3. Tarantino I, Warschkow $\mathrm{R}$, Worni $\mathrm{M}$, et al. Prognostic relevance of palliative primary tumor removal in 37,793 metastatic colorectal cancer patients: a population-based, propensity score-adjusted trend analysis. Ann Surg 2015;262:112-120.

4. Davies JM, Goldberg RM. Treatment of metastatic colorectal cancer. Semin Oncol 2011;38:552-560.

5. Benson AB III, Venook AP, Cederquist $L$, et al. NCCN Clinical Practice Guidelines in Oncology: Colon Cancer. Version 1.2017. Accessed October 19, 2018. To view the most recent version, visit NCCN.org.

6. Bosman FT, Carneiro F, Hruban RH, et al. WHO Classification of Tumours of the Digestive System, 4th ed. Geneva, Switzerland: World Health Organization; 2010.

7. Temple LK, Hsieh L, Wong WD, et al. Use of surgery among elderly patients with stage IV colorectal cancer. J Clin Oncol 2004;22:3475-3484.

8. Alawadi Z, Phatak UR, Hu CY, et al. Comparative effectiveness of primary tumor resection in patients with stage IV colon cancer. Cancer 2017;123: 1124-1133.

9. Ahmed S, Leis A, Fields A, et al. Survival impact of surgical resection of primary tumor in patients with stage IV colorectal cancer: results from a large population-based cohort study. Cancer 2014;120:683-691.

10. Clancy C, Burke JP, Barry M, et al. A meta-analysis to determine the effect of primary tumor resection for stage IV colorectal cancer with unresectable metastases on patient survival. Ann Surg Oncol 2014;21:3900-3908.

11. Faron M, Pignon JP, Malka D, et al. Is primary tumour resection associated with survival improvement in patients with colorectal cancer and unresectable synchronous metastases? A pooled analysis of individual data from four randomised trials. Eur J Cancer 2015:51:166-176.

12. Gresham G, Renouf DJ, Chan M, et al. Association between palliative resection of the primary tumor and overall survival in a population-based cohort of metastatic colorectal cancer patients. Ann Surg Oncol 2014;21: 3917-3923.
13. Venderbosch S, de Wilt JH, Teerenstra S, et al. Prognostic value of resection of primary tumor in patients with stage IV colorectal cancer: retrospective analysis of two randomized studies and a review of the literature. Ann Surg Oncol 2011;18:3252-3260.

14. Adam R, Delvart V, Pascal G, et al. Rescue surgery for unresectable colorectal liver metastases downstaged by chemotherapy: a model to predict long-term survival. Ann Surg 2004;240:644-657, discussion 657-658.

15. Adam R. Chemotherapy and surgery: new perspectives on the treatment of unresectable liver metastases. Ann Oncol 2003;14(Suppl 2):ii13-16.

16. Scheer MG, Sloots CE, van der Wilt GJ, et al. Management of patients with asymptomatic colorectal cancer and synchronous irresectable metastases. Ann Oncol 2008;19:1829-1835.

17. Scoggins $C R$, Meszoely IM, Blanke CD, et al. Nonoperative management of primary colorectal cancer in patients with stage IV disease. Ann Surg Oncol 1999;6:651-657.

18. Krell RW, Regenbogen SE, Wong SL. Variation in hospital treatment patterns for metastatic colorectal cancer. Cancer 2015;121:1755-1761.

19. Healy MA, Pradarelli JC, Krell RW, et al. Variation in primary site resection practices for advanced colon cancer: a study using the National Cancer Data Base. Am J Surg 2016;212:579-586.

20. Ward MM, Ullrich F, Matthews K, et al. Access to chemotherapy services by availability of local and visiting oncologists. JCO Oncol Pract 2014;10: 26-31

21. Chow CJ, Al-Refaie WB, Abraham A, et al. Does patient rurality predict quality colon cancer care? A population-based study. Dis Colon Rectum 2015;58:415-422.

22. American Society of Clinical Oncology. The state of cancer care in America, 2014: a report by the American Society of Clinical Oncology. JCO Oncol Pract 2014;10:119-142.

23. Charlton M, Schlichting J, Chioreso C, et al. Challenges of rural cancer care in the United States. Oncology (Williston Park) 2015;29. 633-640.

24. White A, Joseph D, Rim SH, et al. Colon cancer survival in the United States by race and stage (2001-2009): findings from the CONCORD-2 study. Cancer 2017;123(Suppl 24):5014-5036.

25. Baldwin LM, Dobie SA, Billingsley $K$, et al. Explaining black-white differences in receipt of recommended colon cancer treatment. J Nat Cancer Inst 2005;97:1211-1220. 